DOI: http://doi.org/10.21698/simi.2018.fp01

\title{
A VARIANT OF GREEN CONCRETE WITH INDUSTRIAL AND AGRICULTURAL WASTE
}

Catalina Mihaela Helepciuc (Gradinaru), Marinela Barbuta, Adrian Alexandru Serbanoiu, Andrei Burlacu

"Gheorghe Asachi” Technical University of Iasi, Faculty of Civil Engineering and Building Services, 1 Mangeron Blvd., 700050, Iasi, serbanoiu.adrian@tuiasi.ro, Romania

\begin{abstract}
The research presented in this paper aim to analyze the effects of cement replacement by fly ash in $10 \mathrm{vol}$. \%, 20 vol. \%, and 30 vol. \% and, afterwards, the effects of mineral aggregates substitution by $50 \mathrm{vol}$. \% with vegetal aggregates. The used vegetal aggregates were shredded corn cobs, and were investigated the density, the compressive and split tensile strength of concrete. The results revealed that fly ash, as cement partial replacement, decreased the compressive strength comparing to the reference concrete, meanwhile, the splitting tensile strength was improved when were used $10 \%$ and $20 \%$ vol. of fly ash. Fly ash had a positive effect on the compressive strength of the vegetal concrete, in the case of the composition with $10 \%$ and $30 \%$ vol. of industrial waste, and also on splitting tensile strength in the case of $10 \%$ and $20 \%$ vol. of replacement rate. The concrete density diminished with $1.67 \%, 3.12 \%$ and $3.82 \%$ in the case of $10 \%, 20 \%$ and $30 \%$ vol. cement replacement by fly ash, respectively. Corn cob aggregates led to a concrete density decreasing with almost $25 \%$ compared to reference concrete.
\end{abstract}

Keywords: corn cob, density, fly ash, mechanical properties

\section{Introduction}

Today, in our society, the accent is put more and more on sustainability, environment protection and $\mathrm{CO}_{2}$ emissions decreasing. That is why, in terms of concrete production, the most used material in the construction industry, has become a must to make it as environmentally friendly as possible. This can be achieved by partially replace the cement and/or aggregates from its composition by industrial and agricultural waste. Fly ash, because there are very high quantities of waste disposed as landfill, and corn cobs, because they represent an easy renewable natural resource.

Fly ash is an industrial waste generated by the thermal plants, in quantities equal to $30-40 \%$ of the burned coal (Sun et al 2003), that is usually placed into landfills and becoming, in this way, a threaten for the environment (Aprianti 2017).

The concrete with fly ash represents an ecologic material that has been studied a lot up to now, but in this paper it is presented as reference for a concrete with vegetal aggregates and fly ash. Fly ash was used in the corn cob concrete in order to enhance its properties.

Used as cement partial replacement, fly ash has, in general, positive effects on the strength, sulphate action resistance, permeability and workability of the concrete (Badur \& Chaudhary 2008), but this depends on its properties derived from the 


\section{INTERNATIONAL SYMPOSIUM "THE ENVIRONMENT AND THE INDUSTRY", SIMI 2018, PROCEEDINGS BOOK}

combustion method and type of coal used (Aprianti 2017). Also, it decrease the hydration heat, this being an advantage for the mass structures (Meyer 2009).

Corn cobs represent an agricultural waste that is, either burned on the field (Pinto et al 2012a), either used as such as fertilizer on the harvested field (Ashour et al 2013). The corn cob aggregates can be used for obtaining a lightweight and sustainable ecoconcrete, they having a density of only $212 \mathrm{~kg} / \mathrm{m}^{3}$ (Pinto et al 2012a). The use of different kind of vegetal aggregates for such purposes is the subject of many researches all over the world. The advantages of vegetals in concrete composition are represented by their renewability, low cost and sustainability (Saxena et al 2011). They also ensure thermal (Paiva et al 2012) and acoustic (Asdrubali 2007) insulation properties. The concrete with corn cobs as conventional aggregates replacement, in particular, has not been very studied up to now. Faustino et al (2015) used corn cob granules coated with cement paste in concrete composition, and obtained a lightweight material with a density of $1680 \mathrm{~kg} / \mathrm{m}^{3}$; this low density was accompanied by compressive strength decrease compared to normal concrete made with conventional aggregates, sand and gravel. Pinto et al (2012b) studied the concrete with granulated corn cobs with bigger dimensions than those used by Faustino et al (2015), in a ratio of 6/1/1 (corn cob granules/ Portland cement/ water), obtaining a material with a density of $382.2 \mathrm{~kg} / \mathrm{m}^{3}$, and a compressive strength of $120 \mathrm{kN} / \mathrm{m}^{2}$.

The research presented in this paper aim to analyse the effects of cement replacement by fly ash in $10 \mathrm{vol}$. \%, $20 \mathrm{vol}$. \%, and 30 vol. \% and, afterwards, the effects of mineral aggregates substitution by 50 vol.\% with vegetal aggregates.

\section{Materials and Methods}

The start point of the research was a reference concrete of 25/30 strength class, and on this basis, were developed concrete recipes with $10 \mathrm{vol}$. \%, $20 \mathrm{vol}$. \% and $30 \mathrm{vol}$. $\%$ cement replacement by FA, a concrete recipe with $50 \mathrm{vol}$. \% of mineral aggregates replacement by corn cob aggregates and than these two variants were combined in order to study interconnection between fly ash and corn cobs.

The ingredients of the studied concrete recipes were as follows:

- natural sand (diameter 0-4 mm);

- river gravel (diameter 4-8 $\mathrm{mm}$ );

- cement type CEM II, with mineral additives and of 42.5R MPa strength,

- fly ash from CET Holboca, Iasi;

- two types of additives (a super plasticizer and an accelerator for concrete hardening);

- vegetal aggregates of corn cobs, shredded in granules smaller than 5-6 mm in diameter.

The developed variants of concrete were:

- RC - a reference concrete of 25/30 strength Class (manufactured according to NE012-1:2007);

- CFA10 - a concrete with 10 vol.\% of FA as cement partial replacement;

- CFA20 - a concrete with 20 vol.\% of FA as cement partial replacement;

- CFA30 - a concrete with 30 vol.\% of FA as cement partial replacement;

- CCC50 - a concrete with 50 vol.\% of corn cob granules as partial replacement of mineral aggregates; 


\section{INTERNATIONAL SYMPOSIUM "THE ENVIRONMENT AND THE INDUSTRY", SIMI 2018, PROCEEDINGS BOOK}

- CCCFA 50-10 - a concrete with 50 vol.\% of corn cob granules as partial replacement of mineral ones and 10 vol.\% of FA as partial replacement of cement;

- CCCFA 50-20 - a concrete with 50 vol.\% of corn cob granules as partial replacement of mineral ones and 20 vol. $\%$ of FA as partial replacement of cement;

- CCCFA 50-30 - a concrete with 50 vol.\% of corn cob granules as partial replacement of mineral ones and $30 \mathrm{vol}$. \% of FA as partial replacement of cement.

The concrete was poured into cylinder moulds with $100 \mathrm{~mm}$ diameter and $200 \mathrm{~mm}$ length and were made three samples for each recipe. On the resulted samples was measured the apparent density and than were performed tests to determine compressive and splitting tensile strength, according to the norms in force (SR EN 12350-6:2010); (SR EN 12390-3:2009/AC:2011); (SR EN 12390-6:2010); (SR EN 12390-7/AC:2006). Provide sufficient detail to allow the work to be reproduced. Methods already published should be indicated by a reference: only relevant modifications should be described.

\section{Results and Discussion}

\section{Concrete density}

Regarding the evolution of concrete density from casting till 28 days of curing (Figure 1), RC registered a 1.2\% density decreasing and the CCC50 a 8.42\% smaller density. The smallest density decrease of all was registered by CFA 10 , with $0.58 \%$, and the biggest one by CCC50, with $8.42 \%$. From the CFA category, the highest diminish was of CFA20, with $3.74 \%$, and from the CCCFA group, the smallest diminish was of CCCFA50-10, with 4.99\%.

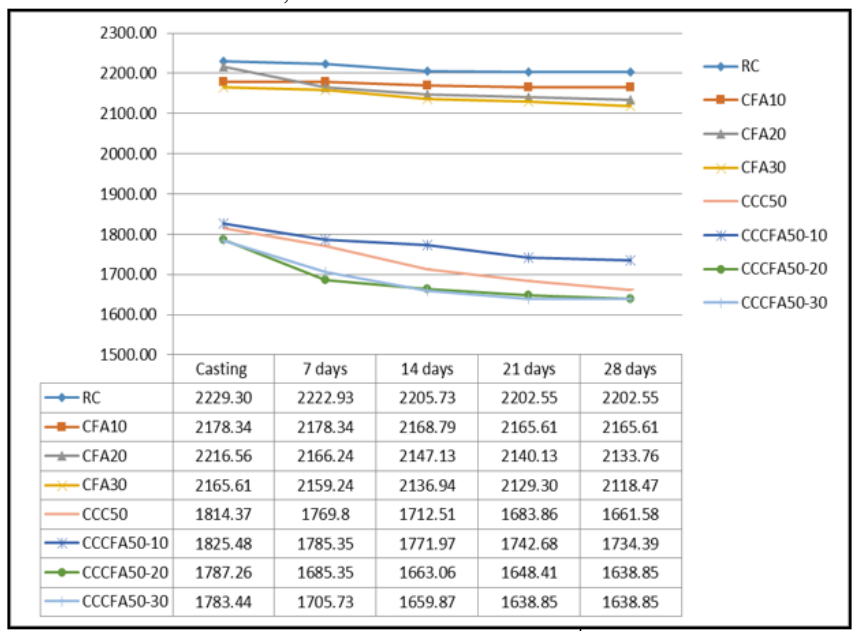

Figure 1. The evolution of concrete density, from casting till 28 days of curing $\left[\mathrm{kg} / \mathrm{m}^{3}\right]$. 


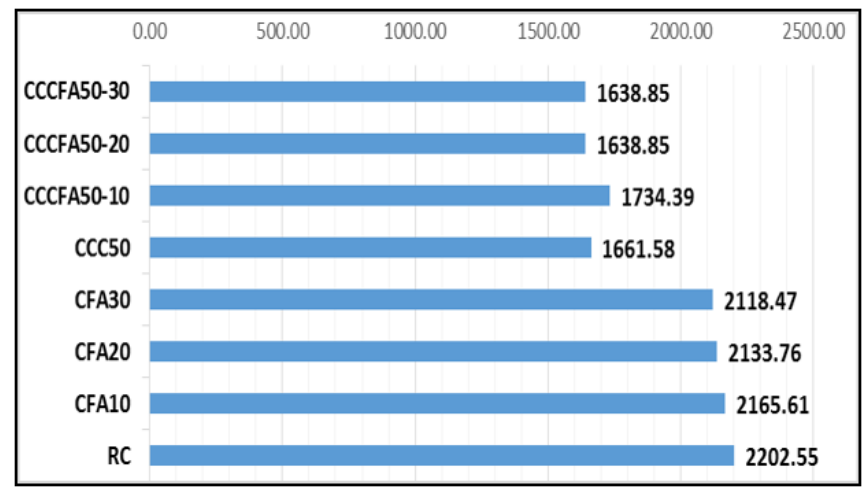

Figure 2. Concrete density at 28days, $\left[\mathrm{kg} / \mathrm{m}^{3}\right]$.

The cement replacement by fly ash determined the density decreasing of the concrete, the smallest density from the CFA group being registered by CFA30 with a value of $2118,47 \mathrm{~kg} / \mathrm{m}^{3}$, with $3.82 \%$ smaller than of the RC (Figure 2). The concrete recipe with corn cobs only registered a density diminish with $24.56 \%$ compared to RC. The group of CCCFA registered density values smaller than 1750 $\mathrm{kg} / \mathrm{m}^{3}$, the decrease being between $25,59 \%$ and $21.25 \%$ compared to RC (Figure 2).

Compressive strength of the concrete

From compressive strength point of view (Figure 3), FA led to the decreasing of this property with $7.98 \%, 17.47 \%$ and $34.19 \%$ for 10 vol. $\%, 20$ vol. $\%$ and 30 vol. $\%$ of cement replacement, respectively. The $50 \mathrm{vol}$. \% of mineral aggregates replaced by corn cob ones determined a strong compressive strength diminish, with $85.90 \%$.

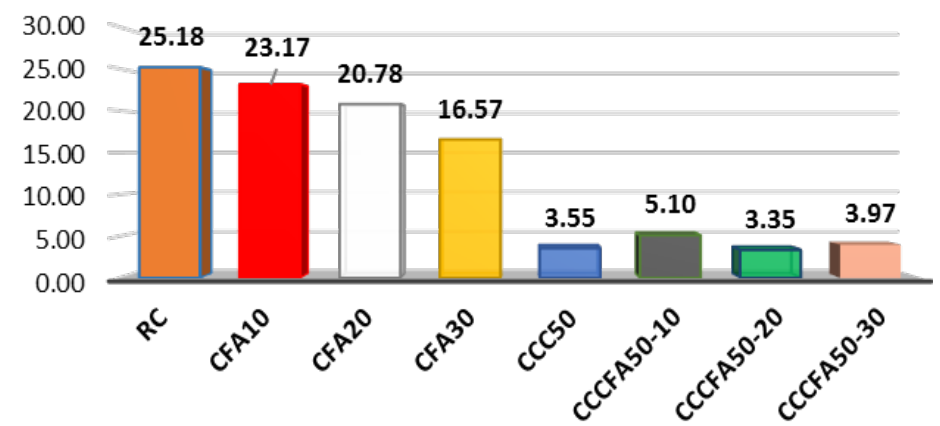

Figure 3. Compressive strength of the concrete $\left[\mathrm{N} / \mathrm{mm}^{2}\right]$.

Fly ash association with corn cob aggregates revealed an improvement of the compressive strength in the case of $10 \mathrm{vol}$. \% and $30 \mathrm{vol}$. \% cement replacement, than CCC50, with $43.66 \%$ and $11.83 \%$, respectively.

Tensile strength of the concrete 


\section{INTERNATIONAL SYMPOSIUM "THE ENVIRONMENT AND THE INDUSTRY", SIMI 2018, PROCEEDINGS BOOK}

Regarding the tensile strength of the studied concrete recipes (Figure 4), FA led to the increase of the splitting tensile strength with $9.39 \%, 15.96 \%$ for 10 vol. \% and $20 \mathrm{vol}$. \% of cement replacement, respectively. The $50 \mathrm{vol}$. \% of mineral aggregates replaced by corn cob ones determined a strong splitting tensile strength diminish, with $76.05 \%$.

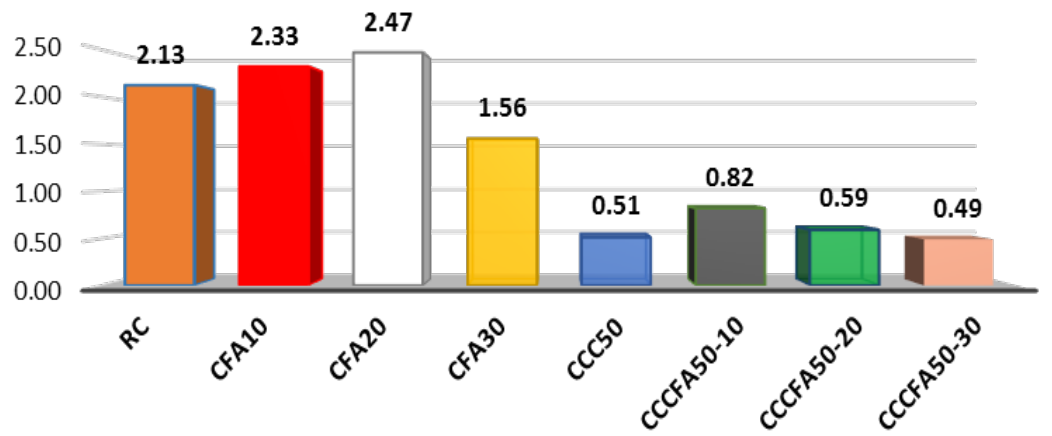

Figure 4. Splitting tensile strength of the concrete $\left[\mathrm{N} / \mathrm{mm}^{2}\right]$.

Fly ash association with corn cob aggregates revealed an improvement of splitting tensile strength in the case of 10 vol. \% and 20 vol. \% cement replacement, with $62.19 \%$ and $15.68 \%$, respectively, than CCC50.

\section{Conclusions}

A source of vegetable waste for building materials is represented by corn cobs. Analyzing the mechanical properties of concretes with corn cob aggregates, these had values much lower compared to the standard concrete. It seems that the association of fly ash with corn cobs aggregates had very positive effects on the vegetal concrete. In conclusion, the use of vegetable waste is adequate to achieve sustainable development in the constructions field. An advantage of these concretes is their weight, the obtained densities fitting them into the category of lightweight concrete which may have non-structural applications such as screeds, plasters or closures in the form of masonry blocks or panels.

\section{Acknowledgements}

The first author is grateful to Sika Romania representatives for their technical support and for providing the necessary additives in order to accomplish the presented research.

\section{References}

Aprianti, ES 2017, 'A huge number of artificial waste material can be supplementary cementitious material (SCM) for concrete production - a review part II', Journal of Cleaner Production, vol. 142, pp. 4178-4194.

Asdrubali, F 2007, 'Green and sustainable materials for noise control in buildings', 19th International Congress on Acoustics, PACS, Madrid, pp. 43-55. 


\section{INTERNATIONAL SYMPOSIUM "THE ENVIRONMENT AND THE INDUSTRY", SIMI 2018, PROCEEDINGS BOOK}

Ashour, A, Amer, M, Marzouk, A, Shimizu, K, Kondo, R \& El-Sharkawy, S 2013, 'Corncobs as a Potential Source of Functional Chemicals', Molecules, vol.18, pp.13823-13830.

Badur, S \& Chaudhary, R 2008, 'Utilization of hazardous wastes and by-products as a green concrete material through S/S process: a review', Reviews on Advanced Materials Science, vol.17, pp. 42-61.

Faustino, J, Silva, E, Pinto, J, Soares, E, Cunha, VMCF \& Soares, S 2015, 'Lightweight concrete masonry units based on processed granulate of corn cob as aggregate', Materiales de Construcción, vol. 65, no. 318, pp. e055.

Meyer, C 2009, 'The greening of the concrete industry', Cement \& Concrete Composites, vol. 31, pp. 601-605.

NE012-1 2007, 'Practice Code for Execution of Concrete Works, Reinforced Concrete and Prestressed Concrete. Part 1: Concrete Production'.

Paiva, A, Pereira, S, Sá, A, Cruza, D, Varum, H \& Pinto, J 2012, 'A contribution to the thermal insulation performance characterization of corncob particleboards', Energy and Buildings, vol. 45, pp. 274-279.

Pinto, J, Cruz, D, Paiva, A, Pereira, S, Tavares, P, Fernandes, L \& Varum, H 2012(a), 'Characterization of corn cob as a possible raw building material', Construction and Building Materials, vol. 34, pp. 28-33.

Pinto, J, Vieira, B, Pereira, H, Jacinto, C, Vilela, P, Paiva, A, Pereira, S, Cunha, VMCF \& Varum, H 2012 (b) ,'Corn cob lightweight concrete for nonstructural applications', Construction and Building Materials, vol. 34, pp. 346-351.

Saxena, M, Pappu, A, Sharma, A, Haque, R \& Wankhede, S 2011, 'Composite Materials from Natural Resources: Recent Trends and Future Potentials', Advances in Composite Materials - Analysis of Natural and Man-Made Materials, Pavla Těšinova Editor, InTech, Rijeka, Croatia.

SR EN 12350-6:2010: Testing fresh concrete, Part 6: Density.

SR EN 12390-3:2009/AC 2011, Testing hardened concrete, Part 3: Compressive strength of test specimens.

SR EN 12390-6:2010, Testing hardened concrete, Part 6: Split tensile strength of test specimens.

SR EN 12390-7/AC: 2006, Testing hardened concrete, Part 7: Density of hardened concrete.

Sun, W, Handong, Y \& Binggen, Z 2003, 'Analysis of mechanism on waterreducing effect of fine ground slag, high-calcium fly ash, and low-calcium fly ash', Cement and Concrete research, vol. 33, pp. 1119-1125. 